\title{
Pseudomonas fluorescens SBW25 produces furanomycin, a non-proteinogenic amino acid with selective antimicrobial properties
}

\author{
Kristin Trippe ${ }^{1}$, Kerry McPhail ${ }^{2}$, Donald Armstrong ${ }^{3}$, Mark Azevedo ${ }^{1}$ and Gary Banowetz ${ }^{1 *}$
}

\begin{abstract}
Background: Pseudomonas fluorescens SBW25 has been extensively studied because of its plant growth promoting properties and potential as a biocontrol agent. The genome of SBW25 has been sequenced, and among sequenced strains of pseudomonads, SBW25 appears to be most closely related to P. fluorescens WH6. In the authors' laboratories, WH6 was previously shown to produce and secrete 4-formylaminooxyvinylglycine (FVG), a non-proteinogenic amino acid with selective herbicidal and antimicrobial activity. Although SBW25 does not have the genetic capacity to produce FVG, we were interested in determining whether this pseudomonad might produce some other type of non-proteinogenic amino acid.

Results: $P$. fluorescens SBW25 was found to produce and secrete a ninhydrin-reactive compound with selective antimicrobial properties. This compound was purified from SBW25 culture filtrate and identified as the non-proteinogenic amino acid L-furanomycin [2S,2'R,5'S)-2-amino-2-(5'methyl-2',5'-dihydrofuran-2'-yl)acetic acid].

Conclusions: The identification of furanomycin as a secondary metabolite of SBW25 is the first report of the production of furanomycin by a pseudomonad. This compound was known previously only as a natural product produced by a strain of Streptomyces. This report adds furanomycin to the small list of non-proteinogenic amino acids that have been identified as secondary products of pseudomonads. This study also extends the list of bacteria that are inhibited by furanomycin to include several plant pathogenic bacteria.
\end{abstract}

Keywords: Pseudomonas fluorescens SBW25, Pseudomonas fluorescens WH6, Secondary metabolites, Non-proteinogenic amino acids, Antimicrobial activity, 4-formylaminooxyvinylglycine, Furanomycin

\section{Background}

Pseudomonas fluorescens is a $\gamma$-proteobacterium that is found throughout terrestrial ecosystems but is most commonly isolated from the surface of plant roots and leaves. Strains of $P$. fluorescens are physiologically and ecologically diverse, representing at least five biovars [1]. The extreme heterogeneity among $P$. fluorescens isolates has led scientists to propose that strains of $P$. fluorescens form a complex of species [1-3]. Recent analyses that compare the genomes of several $P$. fluorescens strains support that hypothesis [4] and demonstrate that strains of $P$. fluorescens arose from at least three separate lineages [5].

\footnotetext{
* Correspondence: Gary.Banowetz@ars.usda.gov

'USDA-ARS National Forage Seed Production Research Center, Corvallis, OR 97331, USA

Full list of author information is available at the end of the article
}

The large genomes of $P$. fluorescens provide an extensive biochemical repertoire that enables some strains to produce and secrete bioactive molecules that mediate microbe-microbe, plant-microbe, and insect-microbe interactions [6]. These secondary metabolites include antimicrobial compounds like phenazines, polyketides, cyclic lipopeptides, pyrrolnitrin, hydrogen cyanide, and others [6,7]. Because these compounds may play a critical role in both microbial and plant ecology, there is continuing interest in characterizing secondary metabolites produced by isolates of $P$. fluorescens.

P. fluorescens WH6, a strain originally isolated from the rhizosphere of wheat $[8,9]$, has been shown in our laboratories to produce and secrete a low molecular weight compound that has selective herbicidal and antimicrobial properties $[10,11]$. This compound, which we termed a Germination-Arrest Factor (GAF), selectively 
and irreversibly arrests the germination of a large number of graminaceous species, including a number of invasive grassy weeds [10]. We identified GAF as the nonproteinogenic amino acid 4-formylaminooxyvinylglycine (FVG, L-2-amino-4-formylaminooxy-trans-3-butenoic acid) [12]. FVG was subsequently shown to also have selective antimicrobial activity against a few strains of bacteria (13), including Erwinia amylovora, the bacterial plant pathogen that is the causal agent of the disease of orchard crops known as fireblight.

The genome of $P$. fluorescens WH6 has been sequenced [13] and compared to other sequenced strains of $P$. fluorescens [5,13]. Among sequenced strains of pseudomonads, these comparative genomic and phylogenetic analyses indicated that WH6 was most closely related to SBW25. These two strains appear to represent a distinct clade within the lineage that includes $P$. fluorescens A506 and BG33R [5]. These analyses have shown that $69 \%$ of P. fluorescens WH6 genes have an orthologous sequence in SBW25, and they share extensive long-range synteny [13]. Nonetheless, in spite of the overall similarity of the SBW25 genome to that of WH6, SBW25 lacks a gene cluster we have shown to be essential to the biosynthesis of FVG [14].

P. fluorescens SBW25 was first isolated from the leaf surface of a sugar beet plant [15]. Since then it has been used as a model organism for evolutionary and plant colonization studies [16-20]. SBW25 has also been extensively studied for its plant growthpromoting properties and its ability to protect peas from seedling damping-off caused by the oomycete Pythium ultimatum [21]. The secondary metabolites known to be produced by SBW25 include pyoverdine siderophores [22] and a viscosin-like cyclic lipopeptide [23]. The latter compound exhibits zoosporicidal activity towards a different oomycete, Phytophthora infestans, but its primary role appears to be in biofilm formation and facilitating the surface motility of SBW25 [23].

Although the P. fluorescens SBW25 genome does not contain the gene cluster we have found to be essential for FVG production, the overall similarity of the WH6 and SBW25 genomes attracted our interest in the latter strain and in the possibility that SBW25 might also produce some type of non-proteinogenic amino acid. In the present study, we report that $P$. fluorescens SBW25 produces and secretes a ninhydrin-reactive compound that selectively inhibits the growth of several bacterial plant pathogens. This compound was purified from $P$. fluorescens SBW25 culture filtrates and identified as the amino acid L-furanomycin. To our knowledge, this is only the second report of furanomycin production by a microbe and the first report of furanomycin production by a pseudomonad.

\section{Results}

Presence of ninhydrin-reactive compounds in $P$. fluorescens SBW25 culture filtrate

As a preliminary test for the production of nonproteinogenic amino acids by $P$. fluorescens SBW25, and to compare SBW25 culture filtrates with filtrate from WH6, dried culture filtrates of SBW25 and WH6 were extracted with $90 \%$ ethanol. Aliquots of the concentrated extracts were fractionated by thin-layer chromatography (TLC) on cellulose and silica plates. The resulting chromatograms were then stained with ninhydrin (Figure 1). The extract of SBW25 culture filtrate yielded a single, strongly-staining, ninhydrin-reactive band on both cellulose and silica TLC plates. On cellulose TLC plates, this band exhibited greater mobility than the FVG band visible in the chromatogram of the extract from WH6. On silica TLC plates, the SBW25 band had a slightly lower $\mathrm{R}_{\mathrm{f}}$ than FVG from WH6.

\section{Biological activity of $P$. fluorescens SBW25 culture filtrate} The antimicrobial properties of P. fluorescens SBW25 culture filtrate were tested against a panel of bacteria that included multiple races, pathovars, and strains of eleven bacterial species (Table 1). Of the nineteen bacterial strains tested in our standard agar diffusion assay, six were sensitive to the filtrate as evidenced by a large zone of clearing about the central well containing the SBW25 culture filtrate. These six strains are listed in Table 2 and included five plant pathogens. Typical results of the agar diffusion assay are illustrated in Additional file 1 , which shows results with five of the sensitive strains and one of the insensitive strains tested. Of the strains inhibited by SBW25 culture filtrate, $P$. syringae pv. tomato DC3000 was the most sensitive. However, because $P$. syringae pv. tomato DC3000 harbors its own antibacterial properties [24], we chose Dickeya dadantii 1447, a pathovar that causes bacterial soft rot of corn, to use in following antibiotic activity in subsequent purification work. The bacterial plant pathogens inhibited by SBW25 culture filtrate included Erwinia amylovora, which is also selectively inhibited by culture filtrate from $P$. fluorescens WH6 [25]. However, unlike WH6, SBW25 culture filtrate did not inhibit the germination of Poa апnиa in our standard germination arrest assay [10].

\section{Association of the antimicrobial activity of SBW25 culture filtrate with a ninhydrin-reactive compound}

The possibility that the antimicrobial activity of SBW25 culture filtrates was associated with the ninhydrin-reactive component of the filtrate was examined in additional fractionation studies. Preliminary experiments determined that most of the ninhydrin-reactive compound from SBW25 culture filtrate was extracted from the dried culture filtrate solids by extraction with $85 \%$ ethanol. To determine if the antimicrobial activity of $P$. fluorescens SBW25 culture 

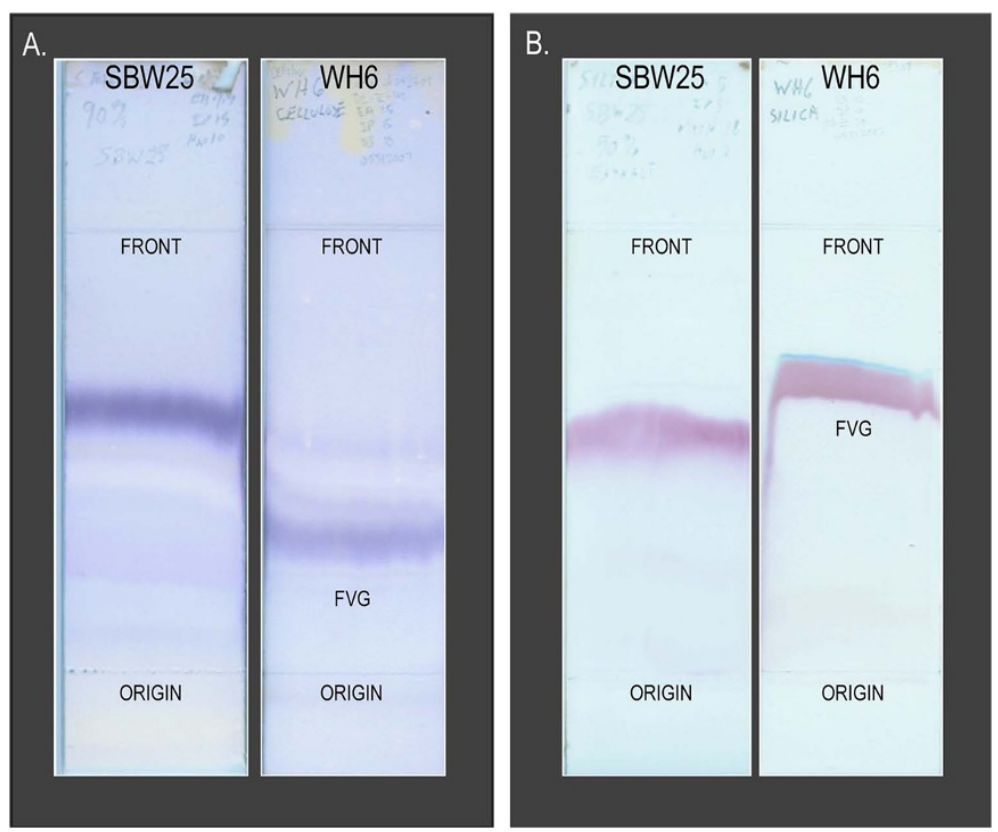

Figure 1 Thin-layer chromatograms of 90\% ethanol extracts of dried culture filtrates from $P$. fluorescens SBW25 and WH6.

A. Ninhydrin-stained cellulose TLC chromatograms. B. Ninhydrin-stained GHL-silica TLC chromatograms. Sample preparation and application and the solvent systems used to develop the chromatograms are described in the Methods section. The ninhydrin band corresponding to FVG is indicated on the WH6 chromatogram.

filtrate could be attributed to the ninhyrin-reactive component of the filtrate, aliquots of the $85 \%$ ethanol extract were fractionated on replicate cellulose TLC plates. One of the chromatograms was stained with ninhydrin, and the remaining cellulose plate was divided into twelve $1-\mathrm{cm}$ zones that were then extracted with water. The resulting extracts were tested for antimicrobial activity in our standard assay. All of the antimicrobial activity towards D. dadantii 1447 was coincident with the position of the ninhydrin-band on the replicate plate (Figure 2). Similar results were obtained with $P$. syringae pv. maculicola M4.

\section{Purification of the ninhydrin-reactive component of SBW25 culture filtrate}

Purification of the ninhydrin-reactive compound from P. fluorescens SBW25 culture filtrate was undertaken by a modification of the strategy used by McPhail et al. [12] to purify FVG. SBW25 culture filtrate $(840 \mathrm{~mL})$ was taken to dryness in vacuo, and the dried solids were extracted with $85 \%$ ethanol. Following evaporation of the $85 \%$ ethanol extract, the solids were dissolved in a small volume of water and applied to a Sephadex G-15 column equilibrated with deionized water for fractionation by ion exclusion chromatography. The elution profile of this column (Figure 3) was monitored by assaying aliquots of each column fraction with ChromeAzurol reagents according to the protocol previously developed by McPhail et al. [12]. The profile exhibited a distinct peak of $\mathrm{Cu}$-binding activity (expected to correspond to compounds containing amino groups) followed by a smaller peak, both of which overlapped an extended peak of Fe-binding activity (reflecting the elution of contaminating phosphate from the culture medium). The fractions corresponding to the larger peak of $\mathrm{Cu}$-binding activity were pooled, taken to dryness in vacuo, and the recovered solids dissolved in $76 \%$ ethanol for preparative TLC fractionation. Following preparative TLC, the area on the TLC plate corresponding to the position of the ninhydrin-reactive compound was scraped from each plate and extracted with deionized water. The combined aqueous extracts were dried in vacuo and dissolved in a small volume of deionized water for rechromatography on a Sephadex G-15 column.

The elution profile for Sephadex G-15 column fractionation of the material recovered from preparative TLC purification exhibited a $\mathrm{Cu}$-binding peak that was clearly separated from a smaller Fe-binding peak, indicating that the ninhydrin-reactive compound was separated from the contaminating phosphate (Figure 4). The fractions from the $\mathrm{Cu}$-binding peak were pooled as indicated, and an aliquot of this pooled material was tested for antimicrobial activity in agar diffusion assays. The tested aliquot strongly inhibited the growth of $D$. dadantii 1447. The pooled fraction was then taken to dryness and re-dissolved in $76 \%$ ethanol. TLC analysis of an aliquot of the $76 \%$ solution gave a single ninhydrin-staining band at the expected $R_{f}$, and no 
Table 1 Bacterial strains tested for sensitivity to $P$. fluorescens SBW25 filtrate

\begin{tabular}{|c|c|c|}
\hline Test species & Strain & Source of strain \\
\hline Agrobacterium tumefaciens & C58bv1 & 2 \\
\hline Bacillus megaterium & $\mathrm{K} 2$ & 1 \\
\hline \multirow[t]{2}{*}{ Dickeya dadantii } & $\times 179$ & 3 \\
\hline & 1447 & 3 \\
\hline Erwinia amylovora & 153 & 1 \\
\hline \multirow[t]{2}{*}{ Escherichia coli } & HB101 & 5 \\
\hline & $\mathrm{DH} 5 \mathrm{a}$ & 5 \\
\hline Pantoea agglomerans & $\mathrm{EH} 252$ & 1 \\
\hline Pectobacterium carotovora & cc101 & 1 \\
\hline \multirow[t]{3}{*}{ Pseudomonas fluorescens } & A506 & 1 \\
\hline & D7 & 6 \\
\hline & WH6 & 7 \\
\hline Pseudomonas marginalis & PM-7 & 2 \\
\hline \multirow[t]{4}{*}{ Pseudomonas syringae } & glycinea race 0,4 & 4 \\
\hline & phaseolicola 1448A & 4 \\
\hline & maculicola M4 & 4 \\
\hline & tomato DC3000 & 4 \\
\hline Stenotrophomonas maltophilia & RM145 & 2 \\
\hline
\end{tabular}

${ }^{1}$ Dr. Joyce Loper (USDA-ARS, Corvallis, OR, USA).

${ }^{2}$ Marilyn Miller (Plant Clinic, Dept. of Botany \& Plant Pathology, Oregon State University, Corvallis, OR, USA).

${ }^{3}$ Dr. Kenneth Johnson (Dept. of Botany \& Plant Pathology, Oregon State University, Corvallis, OR, USA).

${ }^{4}$ Dr. Jeff Chang (Department of Botany \& Plant Pathology, Oregon State University, Corvallis, OR, USA).

${ }^{5}$ commercial source.

${ }^{6}$ Dr. Ann Kennedy (USDA-ARS, Pullman, WA, USA).

${ }^{7}$ Dr. Gary Banowetz (USDA-ARS, Corvallis, OR, USA).

UV-absorbing or fluorescent compounds were detected. The remainder of the $76 \%$ ethanol solution of the purified compound, corresponding to $c a .600 \mathrm{~mL}$ of original culture filtrate, was concentrated in vacuo and yielded $3.7 \mathrm{mg}$ of a white amorphous solid, of which $3.6 \mathrm{mg}$ was dissolved in $500 \mu \mathrm{L}$ of deuterated water $\left(\mathrm{D}_{2} \mathrm{O}\right)$ for nuclear magnetic resonance (NMR) analysis. The remaining $0.1 \mathrm{mg}$ was submitted for high-resolution electrospray mass spectrometry (HRESIMS) to determine molecular composition.

Table 2 Bacteria that are sensitive to $P$. fluorescens SBW25 culture filtrate

\begin{tabular}{lll}
\hline Test species & Strain & Zone size $\mathbf{( \mathbf { c m } ^ { \mathbf { 2 } } )}$ \\
\hline Bacillus megaterium & $\mathrm{K} 2$ & $15.3 \pm 0.22$ \\
\hline Dickeya dadantii & $\mathrm{X} 179$ & $6.7 \pm 0.29$ \\
\hline Erwinia amylovora & 1447 & $10.1 \pm 0.57$ \\
\hline Pseudomonas syringae & 153 & $13.5 \pm 0.34$ \\
\hline & maculicola M4 & $12.2 \pm 1.45$ \\
\hline
\end{tabular}

The sizes of the zones of clearing produced in the lawns of bacteria surrounding the central well containing the filtrate are indicated.

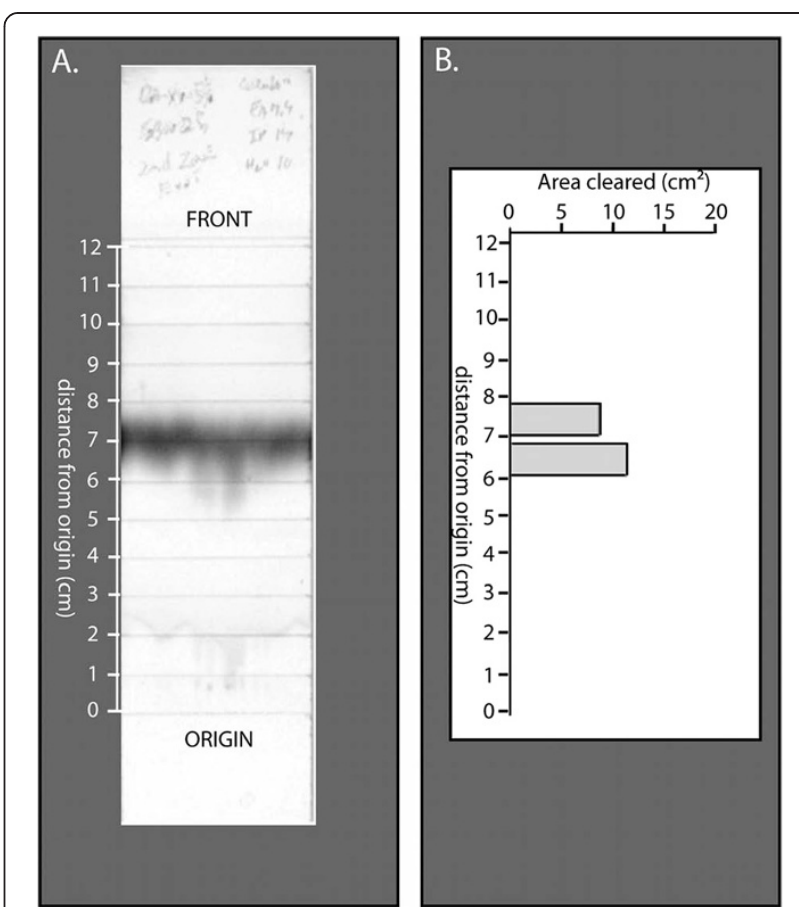

Figure 2 The distribution of antimicrobial activity and ninhydrin-banding after TLC fractionation of an $85 \%$ ethanol extract of dried culture filtrate from P. fluorescens SBW25. The $85 \%$ ethanol extract was prepared and applied to cellulose TLC plates as described in Methods. One of the developed plates was sprayed with ninhydrin (Figure 2A) and the replicate plate was divided into zones, as indicated, for removal and extraction of the cellulose. The aqueous extracts of the cellulose from each zone were assayed for antimicrobial activity according to the standard assay described in the Methods section. The resulting antimicrobial activity against Dickeya dadantii (Figure 2B) was measured after $48 \mathrm{~h}$. Zones without bars did not result in a cleared zone when assayed with either $D$. dadantii or $P$. syringae pv. maculicola M4.

\section{Identification of the purified ninhydrin-reactive compound}

HRESIMS data for the purified compound provided a molecular ion $[\mathrm{M}+\mathrm{H}]^{+}$at $m / z$ 158.0812. Examining the microbial natural products database Antibase 2011, the Natural Compound Identifier (Wiley-VCH) reported 11 nitrogen-containing compounds from a search of the mass range 157.0 to $157.5 \mathrm{Da}$. Six of these were alpha amino acids. Inspection of the ${ }^{1} \mathrm{H}$ NMR spectrum (Additional file 2) for the purified compound revealed an upfield methyl doublet $\left(\delta_{\mathrm{H}} 1.14,3 \mathrm{H}\right)$, and five deshielded multiplets consistent with five heteroatom-substituted or olefinic methines $\left(\delta_{\mathrm{H}} 6.07,5.74,5.34,5.00\right.$ and 3.75 , each $1 \mathrm{H}$ ). These six signals were correlated in a single spin system as judged from the COSY spectrum. Two additional complex multiplets appearing mid-field in the ${ }^{1} \mathrm{H}$ NMR spectrum did not integrate to relative integer values, and showed no COSY correlations to the established spin system. In combination with two additional mid-field 


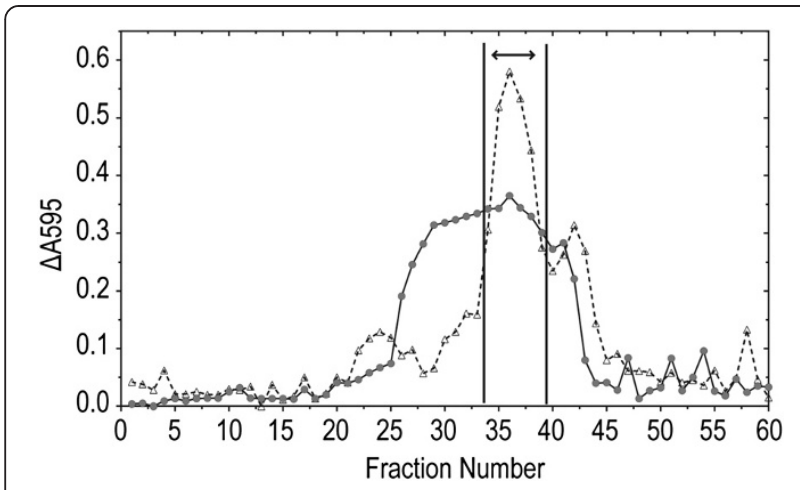

Figure 3 Initial Sephadex G-15 column fractionation of an $85 \%$ ethanol extract of dried culture filtrate from Pseudomonas fluorescens SBW25. The solids from $840 \mathrm{~mL}$ of dried SBW25 culture filtrate were extracted with $85 \%$ ethanol as described in the Methods section. A portion of the extract equivalent to $800 \mathrm{~mL}$ of original culture filtrate was taken to dryness in vacuo and dissolved in $6 \mathrm{~mL}$ of deionized water for application to a Sephadex G-15 column equilibrated in the same solvent. The column was eluted with deionized water. Fractions ( $6 \mathrm{~mL}$ each) were collected and analyzed for reaction with the Fe- and Cu-CAS reagents as described in the Methods section. The fractions corresponding to the largest Cu-binding peak were pooled (as indicated by the double arrow) for concentration and further purification by preparative TLC fractionation.

${ }^{13} \mathrm{C}$ resonances in the ${ }^{13} \mathrm{C}$ NMR spectrum (Additional file 3 ) these ${ }^{1} \mathrm{H}$ signals could be attributed to contaminating glycerol and discounted from further consideration. The ${ }^{13} \mathrm{C}$ NMR spectrum also showed a quaternary ${ }^{13} \mathrm{C}$ signal $\left(\delta_{\mathrm{C}}\right.$ 172.3), as well as Heteronuclear Single Quantum

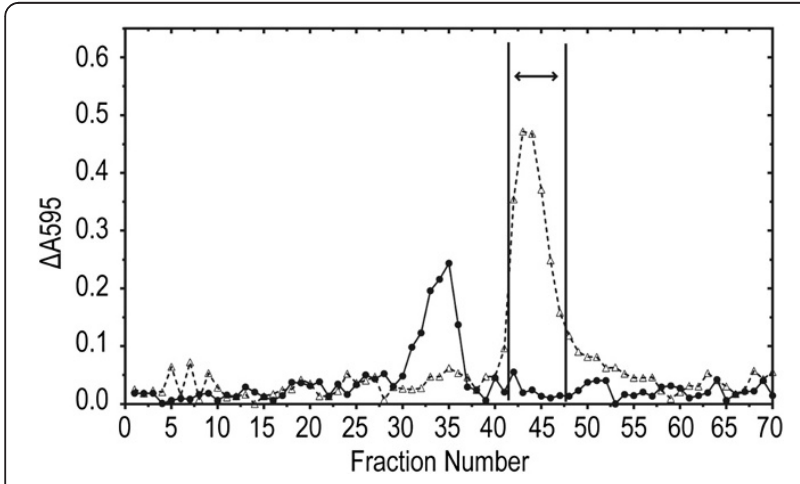

Figure 4 Final Sephadex G-15 column purification of the partially purified ninhydrin-reactive compound recovered from preparative TLC chromatograms. A sterile aqueous solution containing the partially purified SBW25 ninhydrin-reactive compound was prepared by extraction of the appropriate zone of preparative TLC chromatograms as described in the Methods section. This solution was taken to dryness in vacuo, and the recovered solids were dissolved in $5 \mathrm{~mL}$ of deionized water for application to the Sephadex G-15 column. The column was eluted with deionized water. Fractions ( $5 \mathrm{~mL}$ each) were collected and analyzed for reaction with the Fe- and $\mathrm{Cu}$-ChromeAzurol $\mathrm{S}$ reagents. The fractions corresponding to the Cu-binding peak were pooled (as indicated by the double arrow) and concentrated for structural identification
Coherence-correlated resonances for five methines and one methyl carbon in the purified compound. The methine ${ }^{13} \mathrm{C}$ chemical shifts represented two olefinic carbons $\left(\delta_{\mathrm{C}} 136.3\right.$ and 124.3$)$, two oxygenated carbons $\left(\delta_{\mathrm{C}} 84.31\right.$ and 84.24$)$, and an amine-substituted carbon $\left(\delta_{\mathrm{C}} 57.5\right)$. In combination with the HREIMS data, these NMR data support a molecular formula of $\mathrm{C}_{7} \mathrm{H}_{11} \mathrm{NO}_{3}$ and the molecular structure of the alpha amino acid furanomycin (also known as threomycin) [26]. As anticipated, the NMR data for the purified compound matched closely with those reported for L-furanomycin [27] and differed significantly from those for four reported synthetic diastereomers $[28,29]$. Therefore, the $2 S, 2^{\prime} R, 5^{\prime}$ $S$ configuration of L-furanomycin could be assigned, although the presence of the small amount of contaminating glycerol prevented an accurate optical rotation value from being assigned. The molecular structure of L-furanomycin is shown in Figure 5.

\section{Reversal of the antimicrobial activity of SBW25 culture filtrate with selected amino acids}

The ability of furanomycin to inhibit the growth of various bacteria was reported to be reversed by the amino acids leucine, isoleucine, or valine [26]. To determine if the mode of action of furanomycin in inhibiting plant pathogenic bacteria is similar to the mode of action previously described, we added these individual amino acids to SBW25 culture filtrates (10 $\mathrm{mM}$ final concentration) and assayed their ability to inhibit the growth of $D$. dadantii 1447. Glutamine, alanine, and serine, which we had found previously to reverse the effects of FVG in inhibiting the growth of Erwinia amylovora, were also tested in this manner. D. dadantii 1447 was not sensitive to SBW25 culture filtrate containing isoleucine, leucine, or valine (Figure 6, Additional file 4). However, D. dadantii remained sensitive to SBW25 culture filtrate supplemented with glutamine or alanine and to the unmodified filtrate control (Figure 6, Additional file 4). These results indicate that the capacity of $P$. fluorescens SBW25 culture filtrate to inhibit the growth of $D$. dadantii 1447 was reversed in the presence of leucine, isoleucine, and valine, but not glutamine or alanine. The ability of

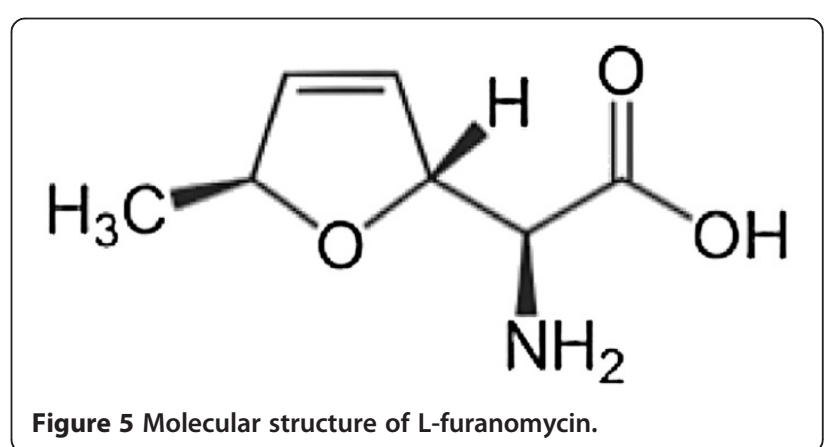




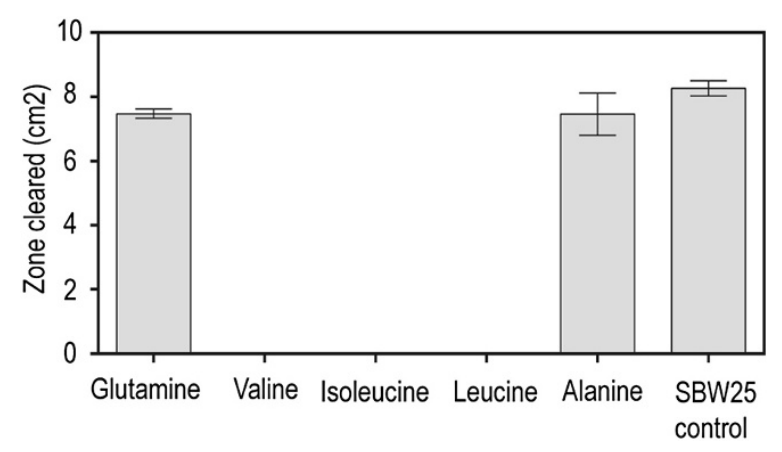

Figure 6 The effect of selected amino acids on the antimicrobial activity of furanomycin. The indicated amino acids were added to aliquots of $P$. fluorescens SBW25 culture filtrate to give a final amino acid concentration of $10 \mathrm{mM}$. The resulting solutions were filter sterilized and tested for antimicrobial activity against $D$. dadantii in our agar diffusion assay as described in the Methods section. The areas of the cleared zones in the bacterial lawns surrounding the central well containing the test solutions are the averages of three replicates. The error bars represent Standard Error of the Mean values.

serine to block antimicrobial activity in these tests was less clear. When serine was added to the culture filtrate, smaller zones of reduced lawn density were observed. However, because these zones were difficult to measure, the data were not included in our statistical analyses.

\section{Discussion}

The identification of furanomycin in P. fluorescens SBW25 culture filtrate is the first report of this compound occurring as a natural product of a pseudomonad. Previously, Streptomyces threomyceticus ATCC 15795 was the only microbe known to produce this antibiotic [26]. The biosynthesis of furanomycin in S. threomyceticus was investigated by Parry and co-workers [30,31], who obtained evidence from feeding studies that the synthesis proceeded via a polyketide pathway that originated from propionate and acetate. Subsequent chemical mutagenic studies suggested that the pathway involved at least six intermediate steps after assembly of the polyketide chain [32]. However, the specific genes affected by these mutations were not identified. The pathway in SBW25 has yet to be investigated.

The identification of furanomycin as a secondary metabolite of $P$. fluorescens SBW25 adds to a small list of non-proteinogenic amino acids that are known to be produced and secreted by pseudomonads. In addition to furanomycin, this list includes FVG, produced by WH6 [12], rhizobitoxine (4-(2-amino-3-hydroxypropoxy) vinylglycine), produced by $P$. andropogonis [33], methoxyvinylglycine (MVG, L-2-amino-4-methoxy-trans3-butenoic acid), produced by $P$. aeruginosa (ATCC-7700) [34,35], and 3-methylarginine, produced by $P$. syringae pv. syringae [36]. We have observed that a number of other strains of pseudomonads produce and secrete ninhydrin-reactive compounds that may represent nonproteinogenic amino acids, but these compounds have yet to be identified.

The non-proteinogenic amino acids identified as secondary metabolites of pseudomonads all display some type of selective antimicrobial properties in in vitro tests. For example, FVG and MVG selectively inhibit the growth of Erwinia amylovora, the causal agent of fireblight, an important disease of roseaceous orchard crops [25,37]. MVG also inhibits growth of Acanthamoeba castellanii [38] and Bacillus sp. 1283B [35]. Likewise, 3-methylarginine suppresses the growth of $P$. syringae pv. glycinia, the causal agent of bacterial leaf blight [36]. Furanomycin has been shown previously to strongly inhibit T-even coliphage, as well as the growth of several microorganisms (Shigella paradysenteriae, Salmonella paratyphi A, and Bacillus subtilis) [26]. Our study expands the known range of bacteria that are susceptible to furanomycin to include several plant pathogens, including D. dadantii, P. syringae, and E. amylovora, as well as the nonpathogenic strain Bacillus megaterium. The specificity of these effects is of particular interest in relation to the potential utility of these organisms for the biocontrol of plant pathogens.

The production of furanomycin by SBW25 appears to account for the selective antibacterial activities of the culture filtrates from this organism grown under our culture conditions. The reversal of these effects in the presence of isoleucine is consistent with previous reports that this antibiotic functions as an isoleucine analog [26] and is recognized by the isoleucyl-tRNA synthetase from Escherichia coli, where it is charged to isoleucine-tRNA and interferes with protein synthesis in that organism [39]. It is less obvious why valine and leucine also interfere with the antibiotic activity of furanomycin, but it is possible that furanomycin interferes with the biosynthesis of branched-chain amino acids, and the presence of an exogenous source of isoleucine, leucine, or valine reverses or compensates for this interference. Whether the numerous pseudomonads and bacterial strains that are insensitive to furanomycin possess isoleucyl-tRNA synthetase activities of more stringent specificity or resist the effects of this antibiotic by other mechanisms remains to be determined.

In addition to their antimicrobial effects, some of the amino acid analogs produced by pseudomonads elicit a response in higher plants. As noted previously, FVG, produced by $P$. fluorescens $\mathrm{WH} 6$, inhibits germination of a large number of graminaceous species [10]. Rhizobitoxine can either act as a phytotoxin (when produced by the plant pathogen Burkholderia andropogonis), or it can facilitate nodulation in host legumes (when produced by the symbiotic nitrogen-fixing bacterium Bradyrhizobium elkanii) [40]. It is not yet known if furanomycin mediates any of the plant growth promoting properties of SBW 25 or 
if it is involved in any other type of plant-microbe interaction.

The biological role that non-proteinogenic amino acids play in pseudomonad physiology and ecology in natural environments has yet to be defined. Phenazine antibiotics have been reported to contribute to the ecological competence of pseudomonads in soil habitats [41], but it is uncertain whether the antimicrobial activities of furanomycin and other amino acid analogs, or the observed effects of some of these compounds on plant growth, are important in natural settings. This class of pseudomonad secondary metabolites has received limited attention to date, and further investigations will be needed to determine their function and importance.

\section{Conclusions}

The results of this study demonstrate that the secondary metabolites produced by $P$. fluorescens SBW25 includes the non-proteinogenic amino acid known as L-furanomycin. This compound is shown here to inhibit the growth of several bacterial strains, including a number of plantpathogenic microbes. Previously, furanomycin was only known to be produced by a single strain of $S$. threomyceticus. The antimicrobial activity of furanomycin observed here was reversed in the presence of exogenous leucine, isoleucine, and valine, which is consistent with the previously reported ability of this compound to act as an isoleucine antagonist. This study adds furanomycin to the small group of non-proteinogenic amino acids that are known to be produced by pseudomonads, suggesting that these compounds may have a more ubiquitous presence and a more universal role in pseudomonad ecology than has been previously recognized.

\section{Methods}

\section{Chemicals and chromatographic materials}

All aqueous ethanol solutions were prepared from $95 \% \mathrm{v} / \mathrm{v}$ ethanol that had been redistilled prior to use. All other solvents were purchased as spectrophotometric grade reagents. Chrome Azurol S (CAS), 2-(N-morpholino) ethanesulfonic acid (MES), ninhydrin, and Sephadex G-15 (medium grade) were purchased from Sigma-Aldrich (St. Louis, MO). All TLC plates were purchased from Analtech, Inc. (Newark, DE).

\section{Biological materials}

Sources of the bacterial species and strains used in this study are listed in Table 1 . All strains were maintained at $-80^{\circ} \mathrm{C}$ in Luria-Bertani liquid medium (LB medium) [42] containing a final concentration of $15 \%$ (v/v) glycerol.

Annual bluegrass seeds (Poa annua L.) were obtained from 1996 mid-Willamette Valley grass seed screenings and were provided by International Seeds, Halsey, OR, and by $\mathrm{C}$ and $\mathrm{R}$ Farm, Tangent, OR. Prior to use, the seeds were cleaned to remove straw and seeds of other species.

\section{Culture filtrate production}

Pseudomonas fluorescens cells were inoculated into the modified Pseudomonas Minimal Salts Medium (PMS medium) described by Banowetz et al. [10], and cultured and harvested as described in the same reference. To prepare culture filtrates, the 7-day $P$. fluorescens cultures were centrifuged $(3000 \times \mathrm{g}, 15 \mathrm{~min})$, and the supernatant was passed through a bacteriological filter (Millipore GP Express Steritop, $0.22 \mu \mathrm{M}$ pore size, Millipore, Billerica, MA). The resulting sterile culture filtrate was stored at $4^{\circ} \mathrm{C}$ prior to use.

\section{Agar diffusion assays for antimicrobial activity}

To test the antimicrobial activity of $P$. fluorescens SBW25 filtrate, bacterial strains were grown overnight in LB medium $(6 \mathrm{~mL})$ at $28^{\circ} \mathrm{C}$ (except for Escherichia coli, which was grown at $\left.37^{\circ} \mathrm{C}\right)$ with shaking $(225 \mathrm{rpm})$. The following morning, the stationary phase bacterial suspensions were adjusted with sterile water to an optical density of 0.2 at $600 \mathrm{~nm}$ (or 0.8 in the case of E. coli) as measured with a Superspec 3000 (Biorad Inc., Hercules, CA). A 300- $\mu \mathrm{L}$ aliquot of the diluted culture was spread onto the surface of a 925 Minimal Medium plate $(100 \times 15 \mathrm{~mm}$, containing $25 \mathrm{~mL}$ of medium). The 925 Minimal Medium [43] was prepared with the modifications described by Halgren et al. [25]. After spreading the bacterial lawn, central wells were punched in the agar with a No. 9 cork borer, and a 300- $\mu \mathrm{L}$ aliquot of SBW25 culture filtrate was dispensed into the well. The plates were incubated for $48 \mathrm{~h}$ at $28^{\circ} \mathrm{C}$, examined, and scored. Zones of inhibition in the area adjacent to the well were quantified with Able Image Analyzer ${ }^{\circ}$ software (MU Labs, Ljublijana, Slovenia). Three replicate plates were prepared for each bacterial strain tested, and the experiment was repeated for any strain that appeared sensitive to the SBW25 filtrate.

\section{Germination arrest assays}

The ability of SBW25 culture filtrate to inhibit the germination of Poa annua seeds was tested according to the protocol described by Banowetz et al. [10].

\section{Ethanol extraction of culture filtrate}

Measured volumes of $P$. fluorescens culture filtrate were taken to dryness in vacuo at a temperature $\leq 45^{\circ} \mathrm{C}$. After evaporation, the dry solids were extracted three times (5 min per extraction) with $90 \%$ or $85 \%(\mathrm{v} / \mathrm{v})$ ethanol as indicated. Each of the three extractions was performed by swirling the solids with a volume of ethanol solution equal to one-third of the original volume of culture filtrate. The three extracts prepared in this manner were combined, taken to dryness in vacuo as described above, dissolved in a 
volume of $76 \%(\mathrm{v} / \mathrm{v})$ ethanol equal to one-twentieth of the original volume of culture filtrate ( $20 \times$ concentration), and stored at $4^{\circ} \mathrm{C}$ for later use.

\section{Analytical thin-layer chromatography (TLC) procedures} Analytical TLC separations were performed on Avicel $^{\odot}$ Microcrystalline Cellulose Uniplates $(5 \times 20 \mathrm{~cm}, 250 \mu \mathrm{m}$ layer, glass-backed) and on Hard-Layer Silica Gel GHL Uniplates $(5 \times 20 \mathrm{~cm}, 250-\mu \mathrm{m}$ layer, glass-backed, with an inorganic binder). For chromatography on cellulose plates, the solvent consisted of ethyl acetate:isopropanol: water (7.5:15:10). For chromatography on silica GHL plates, the solvent consisted of ethyl acetate:isopropanol: methanol:water (5:5:18:2). Unless otherwise indicated, the chromatographic samples ( $200 \mu \mathrm{L}$ of the test solution) were applied to an origin line located $3 \mathrm{~cm}$ from one end of the plate as previously described [11]. The chromatograms were developed over a distance of $12 \mathrm{~cm}$ from the origin. The developed chromatograms were dried and sprayed with a ninhydrin solution consisting of $0.25 \%(\mathrm{w} / \mathrm{v})$ ninhydrin dissolved in $95 \%(\mathrm{v} / \mathrm{v})$ ethanol containing $3.0 \mathrm{~mL}$ of glacial acetic acid per $100 \mathrm{~mL}$ of final solution. Color development was achieved by heating the sprayed chromatograms in an oven at $80-90^{\circ} \mathrm{C}$ for $15 \mathrm{~min}$.

The distribution of antimicrobial activity on the cellulose TLC chromatograms was determined in our standard agar diffusion assay. For this purpose, the chromatogram was divided into twelve $1-\mathrm{cm}$ zones located between the origin and the solvent front. The cellulose from each zone $(1 \times 5 \mathrm{~cm}$ area) was scraped into separate $2.0-\mathrm{mL}$ microfuge tubes, suspended in $1.33 \mathrm{~mL}$ of deionized water, and vortexed repeatedly to give a solution representing a 3 -fold concentration relative to the original culture filtrate. The cellulose was pelleted by centrifugation (10,000 rpm, $10 \mathrm{~min}$, Sorvall MC 12V Minifuge), and the supernatant from each tube was filter sterilized (0. $2 \mu \mathrm{m}$ Acrodisc $13 \mathrm{~mm}$ syringe filter) prior to testing in the agar diffusion assay.

\section{Sephadex G-15 column chromatography}

Sephadex G-15 (107 grams, medium grade) was swollen in deionized water and packed into a column $(2.5 \times 68 \mathrm{~cm}$, $335 \mathrm{~mL}$ bed volume) in the same solvent. The column was washed extensively with deionized water prior to initial sample loading and between column runs. Details of column fractionations are given in the legends to the corresponding figures.

Chrome Azurol S assays of Sephadex G-15 column fractions Aliquots of Sephadex G-15 column fractions were assayed for phosphate (a major contaminant from the medium) and for amino acids using $\mathrm{Fe}$-CAS and $\mathrm{Cu}$-CAS reagents respectively. (The specificities of these reagents are illustrated in Additional files 5 and 6.) The reagents, prepared according to Shenker et al. [44], were composed of $210 \mu \mathrm{M}$ CAS and $200 \mu \mathrm{M}$ of either $\mathrm{CuSO}_{4}$ or $\mathrm{FeSO}_{4}$ in $40 \mathrm{mM}$ MES buffer. The resulting solutions were adjusted to either pH 5.5 (Cu-CAS) or 5.7 (Fe-CAS) with $\mathrm{NaOH}$. To assay column fractions for metal binding, $75 \mu \mathrm{L}$ of the appropriate CAS reagent was mixed with $75 \mu \mathrm{L}$ of a column fraction in each well of a 96-well microtiter plate (Corning Costar No. 3590). The resulting absorbance was measured at $595 \mathrm{~nm}$ in a Bio-Tek EL808 plate reader. The presence of compounds that competed with CAS for metal binding caused a reduction in absorbance. Changes (reductions) in absorbance were measured relative to the most strongly absorbing fraction in the column profile and plotted as indicated.

\section{Preparative TLC procedures}

Preparative TLC separations were performed on Avicel ${ }^{\odot}$ Microcrystalline Cellulose Plates $(20 \times 20 \mathrm{~cm}, 1000 \mu \mathrm{m}$ layer). Prior to use, preparative plates were washed by ascending chromatography in deionized water (twice) followed by one wash with redistilled 95\% ethanol. The plates were dried overnight between washings. The chromatographic samples consisted of $2.0-\mathrm{mL}$ aliquots per plate of a concentrated $76 \%$ ethanol solution (40x concentration) of the solids from the main $\mathrm{Cu}$-binding peak of the Sephadex G-15 fractionation described in the text. The Analtech TLC Sample Streaker was used to apply the sample by repeated streaking across an origin line located $3 \mathrm{~cm}$ from the end of the plate. A filtered air-stream was used to dry the origin for 20 to 30 seconds between applications. Following the last application and prior to development, the plates were allowed to air dry for 8 minutes outside the stream. The plates were developed in $76 \%(\mathrm{v} / \mathrm{v})$ ethanol $(250 \mathrm{~mL}$ solvent in rectangular tanks, dimensions ca. $30 \mathrm{~L} \times 10 \mathrm{~W} \times 26 \mathrm{~cm} \mathrm{H}$ ) over a distance of $12 \mathrm{~cm}$, dried, and examined under UV light $(254 \mathrm{~nm})$. Preliminary experiments determined that the ninhydrin-reactive compound of interest was localized in a narrow band (ca. $1 \mathrm{~cm}$ diameter, $c a . \mathrm{R}_{\mathrm{f}} 0.55$ ) delineated at its leading margin by a narrow UV-absorbing band and bounded at its trailing edge by a narrow fluorescent band immediately preceding a broader UV-absorbing band. These bands were used as markers in purifying the compound by preparative chromatography.

Eight preparative thin-layer plates were used to fractionate the $40 \times$ solution of the material recovered from Sephadex G15 column. The plates were developed with $76 \%$ ethanol. For each chromatogram, the area between the UV-absorbing and UV-fluorescent marker bands was scraped into separate $30-\mathrm{mL}$ Corex centrifuge tubes. Deionized water (10 $\mathrm{mL}$ per tube) was added to each tube. After the tubes were vortexed ( $3 \mathrm{~min}$ ), an additional 10 $\mathrm{mL}$ of deionized water was added to each tube, and the tubes were centrifuged at $6800 \times \mathrm{g}$ in a Sorvall SS34 rotor. 
The supernatants were decanted, pooled, filter sterilized [0. 2- $\mu \mathrm{m}, 25-\mathrm{mm}$ Acrodisc syringe filter (Pall Life Sciences, Ann Arbor, MI)], and stored at $4{ }^{\circ} \mathrm{C}$ prior to final purification by Sephadex G-15 column chromatography.

\section{Structural analysis of purified compound}

NMR data were acquired on a Bruker DRX $300 \mathrm{MHz}$ spectrometer equipped with a $5 \mathrm{~mm}$ BBO NMR probe. Chemical shifts were referenced to tetramethylsilane $\left(\delta_{\mathrm{H}}, \delta_{\mathrm{C}} ; 0,0 \mathrm{ppm}\right)$ in $\mathrm{D}_{2} \mathrm{O}$. HRESIMS data were acquired in positive mode on an AB SCIEX Triple TOF 5600 spectrometer. Optical rotation was measured on a JASCO P-1010 polarimeter.

The observed and calculated HRESIMS and chemical shifts for L-(+)-Furanomycin [(2S,2' $\left.R, 5^{\prime} S\right)$-2-Amino-2(5'-methyl-2',5'-dihydrofuran-2'-yl)acetic Acid, 1] are as follows: HRESIMS $(+)$ obsd $[\mathrm{M}+\mathrm{H}]^{+} \mathrm{m} / z 158.0812$ (calcd for $\left.\mathrm{C}_{7} \mathrm{H}_{11} \mathrm{ON}_{3}, 158.0801\right) ;{ }^{1} \mathrm{H}$ NMR $\left(300 \mathrm{MHz}, \mathrm{D}_{2} \mathrm{O}\right)$ $6.07\left(1 \mathrm{H}, \mathrm{dt}, J=6.2,1.8 \mathrm{~Hz}, \mathrm{H}-4^{\prime}\right), 5.74(1 \mathrm{H}, \mathrm{dt}, J=6.2,1.8$ $\left.\mathrm{Hz}, \mathrm{H}-3^{\prime}\right), 5.34(1 \mathrm{H}, \mathrm{m}), 5.00\left(1 \mathrm{H}, \mathrm{p}, J=6.2 \mathrm{~Hz}, \mathrm{H}-2^{\prime}\right), 3.75$ $(1 \mathrm{H}, \mathrm{d}, J=2.5 \mathrm{~Hz}, \mathrm{H}-2), 1.14\left(1 \mathrm{H}, \mathrm{d}, J=6.4 \mathrm{~Hz}, \mathrm{H}-6^{\prime}\right) ;{ }^{13} \mathrm{C}$ NMR (75 MHz, $\left.\mathrm{D}_{2} \mathrm{O}\right) 172.3$ (C, C-1), $136.3\left(\mathrm{CH}, \mathrm{C}-4^{\prime}\right)$, $124.3\left(\mathrm{CH}, \mathrm{C}-3\right.$ '), $84.31\left(\mathrm{CH}, \mathrm{C}-2^{\prime}\right), 84.24\left(\mathrm{CH}, \mathrm{C}-5^{\prime}\right), 57.5$ $(\mathrm{CH}, \mathrm{C}-2), 21.0\left(\mathrm{CH}_{3}, \mathrm{C}-6^{\prime}\right)$.

\section{Additional files}

Additional file 1: Examples of the observed effects of $P$. fluorescens SBW25 culture filtrate on the growth of lawns of selected bacterial strains. Images of representative agar diffusion assays are shown for five strains of plant pathogens that were sensitive to the filtrate and one representative of strains that did not respond to the filtrate (lower right corner).

Additional file 2: ${ }^{1} \mathrm{H}$ NMR spectrum of the purified ninhydrin-reactive fraction containing L-furanomycin.

Additional file $3:{ }^{13} \mathrm{C}$ NMR spectrum of the purified ninhydrin-reactive fraction containing L-furanomycin.

Additional file 4: Effects of selected amino acids on the antimicrobial activity of $P$. fluorescens SBW25 culture filtrate. Images

of representative agar diffusion assay plates are shown for assays in which the indicated amino acids were added to P. fluorescens SBW25 culture filtrate at a final concentration of $10 \mathrm{mM}$, and aliquots of the resulting solutions were then tested for antimicrobial activity against Dickeya dadantii.

Additional file 5: Specificity of the Chrome Azurol assay. Quantitative data for the reactions of the $\mathrm{Cu}$ and Fe ChromeAzurol reagents with various known compounds are shown.

Additional file 6: Additional tests of the specificity of the Chrome Azurol assay. Quantitative data for the reactions of the $\mathrm{Cu}$ and $\mathrm{Fe}$ ChromeAzurol reagents with various additional known compounds are shown.

\footnotetext{
Abbreviations

GAF: Germination Arrest Factor; FVG: 4-formylaminooxyvinylglycine; TLC: Thin-layer chromatography; NMR: Nuclear magnetic resonance; HRESIMS: High-resolution electrospray mass spectrometry; MVG: Methoxyvinylglycine; CAS: Chrome Azurol S; MES: 2-(N-morpholino) ethanesulfonic acid.
}

\section{Competing interests}

The authors declare that they have no competing interests.

\section{Authors' contributions}

$\mathrm{KT}$ carried out all of the microbiological testing and drafted the manuscript. KM carried out the NMR and other aspects of the structural analyses. MA prepared culture filtrates and carried out the germination assays. DA purified the sample of the compound used for structural analysis. GB participated in the design and coordination of the study and helped draft the manuscript. All of the authors have read and approved the manuscript.

\section{Acknowledgements}

Support from the USDA CSREES Grass Seed Cropping Systems for Sustainable Agriculture Special Grant Program and from the Oregon State University Agricultural Research Foundation is gratefully acknowledged by KM and DA. Technical assistance for parts of this study was provided by Donald D. Chen. The use of trade, firm, or corporation names in this publication is for the information and convenience of the reader. Such use does not constitute an official endorsement or approval by the United States Department of Agriculture or the Agricultural Research Service of any product or service to the exclusion of others that may be suitable.

\section{Author details}

'USDA-ARS National Forage Seed Production Research Center, Corvallis, OR 97331, USA. ${ }^{2}$ College of Pharmacy, Oregon State University, Corvallis, OR 97331, USA. ${ }^{3}$ Department of Botany and Plant Pathology, Oregon State University, Corvallis, OR 97331, USA.

Received: 24 December 2012 Accepted: 7 May 2013

Published: 20 May 2013

\section{References}

1. Bossis E, Lemanceau P, Latour X, Gardan L: The taxonomy of Pseudomonas fluorescens and Pseudomonas putida: current status and need for revision. Agronomie 2000, 20:51-63.

2. Yamamoto S, Kasai H, Arnold DL, Jackson RW, Vivian A, Harayama S: Phylogeny of the genus Pseudomonas: intrageneric structure reconstructed from the nucleotide sequences of gyrB and $r p o D$ genes. Microbiol 2000, 146:2385-2394.

3. Silby MW, Winstanley C, Godfrey SAC, Levy SB, Jackson RW: Pseudomonas genomes: diverse and adaptable. FEMS Microbiol Rev 2011, 35:652-680.

4. Silby MW, Cerdñeo-Tárraga AM, Vernikos GS, Giddens SR, Jackson RW, Preston GM, Zhang X-X, Moon CD, Gehrig SM, Godfrey SAC, Knight CG, Malone JG, Robinson Z, Spiers AJ, Harris S, Challis GL, Yaxley AM, Harris D, Seeger K, Murphy L, Rutter S, Squares R, Quail MA, Saunders E, Mavromatis K, Brettin TS, Bentley SD, Hothersall J, Stephens E, Thomas CM, Parkhill J, Levy SB, Rainey PB, Thomson NR: Genomic and genetic analyses of diversity and plant interactions of Pseudomonas fluorescens. Genome Biol 2009, 10:R51.

5. Loper JE, Hassan KA, Mavrodi DV, Davis EW II, Lim CK, Shaffer BT, Elbourne LD, Stockwell VO, Hartney SL, Breakwell K, Henkels MD, Tetu SG, Rangel LI, Kidarsa TA, Wilson NL, van de Mortel JE, Song C, Blumhagen R, Radune D, Hostetler JB, Brinkac LM, Durkin AS, Kluepfel DA, Wechter WP, Anderson AJ, Kim YC, Pierson LS III, Pierson EA, Lindow SE, Kobayashi DY, Raaijmakers JM, Weller DM, Thomashow LS, Allen AE, Paulsen IT: Comparative genomics of plant-associated Pseudomonas spp.: insights into diversity and inheritance of traits involved in multitrophic interactions. PLOS Genet 2012, 8(7):e1002784.

6. Gross H, Loper JE: Genomics of secondary metabolite production by Pseudomonas spp. Nat Prod Rep 2009, 26:1408-1446.

7. Lesinger T, Margraff R: Secondary metabolites of fluorescent pseudomonads. Microbiol Rev 1979, 43:422-442.

8. Elliott LF, Lynch JM: Plant growth-inhibitory pseudomonads colonizing winter wheat (Triticum aestivum L.) roots. Plant Soil 1985, 84:57-65.

9. Elliott LF, Azevedo MD, Mueller-Warrant GW, Horwath WR: Weed control with rhizobacteria. Soil Sci Agrochem Ecol 1998, 33:3-7.

10. Banowetz GM, Azevedo MD, Armstrong DJ, Halgren AB, Mills DI: Germination-Arrest Factor (GAF): biological properties of a novel, naturally-occurring herbicide produced by selected isolates of rhizosphere bacteria. Biol Control 2008, 46:380-390.

11. Armstrong D, Azevedo M, Mills D, Bailey B, Russell B, Groenig A, Halgren A, Banowetz G, McPhail K: Germination-Arrest Factor (GAF): 3. Determination that the herbicidal activity of GAF is associated with a ninhydrin-reactive compound and counteracted by selected amino acids. Biol Control 2009, 51:181-190 
12. McPhail KL, Armstrong DJ, Azevedo MD, Banowetz GM, Mills Dl: 4-Formylaminooxyvinylglycine, an herbicidal germination-arrest factor from Pseudomonas rhizosphere bacteria. J Nat Prod 2010, 73:1853-1857.

13. Kimbrel JA, Givan SA, Halgren AB, Creason AL, Mills DI, Banowetz GM, Armstrong DJ, Chang $\mathrm{JH}$ : An improved, high-quality draft genome sequence of the Germination-Arrest Factor-producing Pseudomonas fluorescens WH6. BMC Genomics 2010, 11:522.

14. Halgren A, Maselko M, Azevedo M, Mills D, Armstrong D, Banowetz G. Genetics of germination-arrest factor (GAF) production by Pseudomonas fluorescens WH6: Identification of a gene cluster essential for GAF biosynthesis. Microbiol 2013, 159:36-45

15. De Leij F, Sutton EJ, Whipps JM, Fenlon JS, Lynch JM: Impact of field release of genetically modified Pseudomonas fluorescens on indigenous microbial populations of wheat. Appl Environ Microbiol 1995, 61:3443-3453.

16. Rainey PB, Bailey MJ: Physical and genetic map of the Pseudomonas fluorescens SBW25 chromosome. Mol Microbiol 1996, 19:521-533.

17. Kassen R, Llewellyn M, Rainey PB: Ecological constraints on diversification in a model adaptive radiation. Nature 2004, 431:984-988.

18. Rainey PB, Rainey K: Evolution of cooperation and conflict in experimental bacterial populations. Nature 2003, 425:72-74.

19. Zhang X-X, Rainey PB: The role of a P1-type ATPase from Pseudomonas fluorescens SBW25 in copper homeostasis and plant colonization. $\mathrm{Mol}$ Plant Microbe Interact 2007, 20:581-588.

20. Giddens SR, Jackson RW, Moon CD, Jacobs MA, Zhang X-X, Gehrig SM, Rainey PB: Mutational activation of niche-specific genes provides insight into regulatory networks and bacterial function in a complex environment. Proc Nat Acad Sci 2007, 104:18247-18252.

21. Naseby DC, Way JA, Bainton NJ, Lynch JM: Biocontrol of Pythium in the pea rhizosphere by antifungal metabolite producing and non-producing Pseudomonas strains. J Appl Microbiol 2001, 90:421-429.

22. Moon CD, Zhang X-X, Matthijs S, Schäfer M, Budzikiewicz $H$, Rainey PB: Genomic, genetic and structural analysis of pyoverdine-mediated iron acquisition in the plant growth-promoting bacterium Pseudomonas fluorescens SBW25. BMC Microbiol 2008, 8:7.

23. De Bruijn I, De Kock MJD, Yang M, De Waard P, Van Beek TA, Raaijmakers JM: Genome-based discovery, structure prediction and functional analysis of cyclic lipopeptide antibiotics in Pseudomonas species. Mol Microbiol 2007, 63:417-428

24. Haapalainen M, Mosorin H, Dorati F, Wu R-F, Roine E, Taira S, Nissinen R, Mattinen L, Jackson R, Pirhonen M, Lin N-C: Hcp2, a secreted protein of the phytopathogen Pseudomonas syringae pv. tomato DC3000, is required for fitness for competition against bacteria and yeasts. J Bacteriol 2012, 194:4810-4822.

25. Halgren A, Azevedo M, Mills D, Armstrong D, Thimmaiah M, McPhail K, Banowetz G: Selective inhibition of Erwinia amylovora by the herbicidally active germination-arrest factor (GAF) produced by Pseudomonas bacteria. J Appl Microbiol 2011, 111:949-959.

26. Katagiri K, Tori K, Kimura Y, Yoshida T, Nagasaki T, Minato H: A new antibiotic. Furanomycin, an isoleucine antagonist. J Med Chem 1967, 10:1 149-1154.

27. Joullié MM, Wang PC, Semple JE: Total synthesis and revised structural assignment of (+)-furanomycin. J Am Chem Soc 1980, 102:887-889.

28. Semple JE, Wang PC, Lysenko Z, Joullié MM: Total synthesis of (+)-furanomycin and stereoisomers. J Am Chem Soc 1980, 102:7505-7510.

29. Zimmermann PJ, Lee JY, Hlobilova I, Endermann R, Häbich D, Jäger V: Synthesis of L-furanomycin and its analogues via furoisoxazolines. Eur J Org Chem 2005, 2005:3450-3460.

30. Parry RJ, Buu HP: Investigations of the biosynthesis of furanomycin. Unexpected derivation from acetate and propionate. J Am Chem Soc 1983, 105:7446-7447.

31. Parry RJ, Turakhia R, Buu HP: The biosynthesis of furanomycin: on the mechanism of formation of the ether linkage. J Am Chem Soc 1988, 110:4035-4036

32. Parry RJ, Yang N: Isolation and characterization of furanomycin nonproducing Streptomyces threomyceticus mutants. J Antibiot (Tokyo) 1992, 45:1161-1166.

33. Mitchell RE, Frey EJ, Benn MH: Rhizobitoxine and L-threo -hydroxythreonine production by the plant pathogen Pseudomonas andropogonis. Phytochemistry 1986, 25:2711-2715.

34. Sahm U, Knobloch $G$, Wagner F: Isolation and characterization of the methionine antagonist L-2-amino-4-methoxy-trans-3-butenoic acid from Pseudomonas aeruginosa grown on $n$-paraffin. J Antibiot (Tokyo) 1973, 26:389-390.
35. Scannell JP, Pruess DL, Demny TC, Sello LH, Williams T, Stempel A: Antimetabolites produced by microorganisms. V. L-2-Amino-4-methoxytrans-3-butenoic acid. J Antibiot (Tokyo) 1972, 25:122-127.

36. Braun SD, Völksch B, Nüske J, Spiteller D: 3-Methylarginine from Pseudomonas syringae pv. syringae $22 \mathrm{~d} / 93$ suppresses the bacterial blight caused by its close relative Pseudomonas syringae pv. glycinea. ChemBioChem 2008, 9:1913-1920

37. Lee X, Azevedo MD, Armstrong DJ, Banowetz GM, Reimmann C: The Pseudomonas aeruginosa antimetabolite L-2-amino-4-methoxy-trans-3butenoic acid inhibits growth of Erwinia amylovora and acts as a seed germination arrest factor. Environ Microbiol Rep 2013, 5:83-89.

38. Lee X, Reimmann C, Greub G, Sufrin J, Croxatto A: The Pseudomonas aeruginosa toxin L-2-amino-4-methoxy-trans-3-butenoic acid inhibits growth and induces encystment in Acanthamoeba castellanii. Microbes Infect 2012, 14:268-272.

39. Kohno T, Kohda D, Haruki M, Yokoyama S, Miyazawa T: Nonprotein amino acid furanomycin, unlike isoleucine in chemical structure, is charged to isoleucine tRNA by isoleucyl-tRNA synthetase and incorporated into protein. J Biol Chem 1990, 265:6931-6935.

40. Sugawara M, Okazaki S, Nukui N, Ezura H, Mitsui H, Minamisawa K: Rhizobitoxine modulates plant-microbe interactions by ethylene inhibition. Biotechnol Adv 2006, 24:382-388

41. Mazzola M, Cook RJ, Thomashow LS, Weller DM, Pierson LS 3rd: Contribution of phenazine antibiotic biosynthesis to the ecological competence of fluorescent pseudomonads in soil habitats. Appl Environ Microbiol 1992, 58:2616-2624.

42. Sambrook JF, Russell DW: Molecular cloning: A laboratory manual. 3rd edition. Cold Spring Harbor, NY: Cold Spring Harbor Laboratory Press; 2001.

43. Langley RA, Kado Cl: Studies on Agrobacterium tumefaciens. Conditions for mutagenesis by $\mathrm{N}$-methyl- $\mathrm{N}$ '-nitro-N-nitrosoguanidine and relationships of $A$. tumefaciens to crown-gall tumor induction. Mutat Res 1972, 14:277-286.

44. Shenker $M$, Chen $Y$, Hadar $Y$ : Rapid method for accurate determination of colorless siderophores and synthetic chelates. Soil Sci Soc Am J 1995, 59:1612-1618.

doi:10.1186/1471-2180-13-11

Cite this article as: Trippe et al:: Pseudomonas fluorescens SBW25 produces furanomycin, a non-proteinogenic amino acid with selective antimicrobial properties. BMC Microbiology 2013 13:111.

\section{Submit your next manuscript to BioMed Central and take full advantage of:}

- Convenient online submission

- Thorough peer review

- No space constraints or color figure charges

- Immediate publication on acceptance

- Inclusion in PubMed, CAS, Scopus and Google Scholar

- Research which is freely available for redistribution
C Biomed Central 